Original Research Article

\title{
Assessment of drug use practices among dermatology out-patients using WHO core drug use indicators
}

\author{
Shatavisa Mukherjee ${ }^{1 *}$, Nikhil Era ${ }^{2}$, Gautam Banerjee ${ }^{3}$, Santanu Kumar Tripathi1
}

\begin{abstract}
${ }^{1}$ Department of Clinical \& Experimental Pharmacology, Calcutta School of Tropical Medicine, Kolkata, West Bengal, India

${ }^{2}$ Department of Pharmacology, MGM Medical College \& LSK Hospital, Kishanganj, Bihar, India

${ }^{3}$ Department of Dermatology, Venereology and Leprology, Calcutta School of Tropical Medicine, Kolkata, West Bengal, India
\end{abstract}

Received: 10 October 2017 Accepted: 01 November 2017

\section{*Correspondence to:}

Ms. Shatavis a Mukherjee, Email: shatavisa100@ gmail.com

Copyright: (C) the author(s), publisher and licensee Medip Academy. This is an openaccess article distributed under the terms of the Creative Commons Attribution NonCommercial License, which permits unrestricted noncommercial use, distribution, and reproduction in any medium, provided the original work is properly cited.

\begin{abstract}
Background: Considering the economic burden the skin diseases cause owing to its high prevalence, it is of interest to periodically monitor the drug use pattern so as to increase the therapeutic efficacy, decrease adverse effects and provide feedback to prescribers. The present study thus assessed the drug use practices among dermatology outpatients in a tertiary care teaching unit in Eastern India. Methods: The study as sessed drug use practices for all prescriptions of patients attending the concerned OPD using WHO core drug use indicators which consist of mainly three domains, prescribing indicators, patient care indicators and healthcare indicators.

Results: Total number of drugs in 471 prescriptions was found to be 1050 . Number of drugs per prescription varied from 1 to 6 with average of 2.22. The most commonly prescribed drugs were antibiotics, followed by steroids and steroidal combinations. Prescribing indicators revealed that $2.09 \%$ drugs were generic prescribing, with about $18.78 \%$ of the drugs being prescribed from the WHO essentialdrug list. The proportion of encounters with at least one antibiotic prescribed was $34.82 \%$. $13.9 \%$ drugs actually dispensed from hospital supply, of which all were adequately labelled.

Conclusions: Increasing dermatological prescribing has necessitated as sessment of their rational usage. Promoting rational drug use policy is recommended for effective healthcare management.
\end{abstract}

Keywords: Drug use practices, Essential drug list, Rational prescribing, WHO core drug use indicators

\section{INTRODUCTION}

With the spurge of basic and clinical research activities, and the subsequent recognition of newer dermatological disorders; dermatology, venereology and leprology is now considered to be the one of the most important specialties in a healthcare setup. The skin, the largest organ of the body, epitomize for most of the underlying internal diseases. Dermatological conditions accounts for up to $2 \%$ of consultations in general practice worldwide. ${ }^{1}$ Dermatological problem in India manifests as primary and secondary cutaneous complaints. ${ }^{2}$ In India the most prevalent dermatological condition includes dermatitis, 
urticaria, fungal skin infection, acne, alopecia, psoriasis, skin cancer and drug rash.

The most crucial phase of pharmacotherapy of any disease is its appropriate diagnosis followed by rational prescribing of drugs. Irrational polypharmacy accounts for $28 \%$ of adverse drug reactions and also stimulate inappropriate patient demand leading to reduced access and attendance rates due to medicine stock outs and loss of patient confidence in health. ${ }^{3}$ It has been estimated that $50 \%$ or more medicine expenditure is being wasted through irrational prescribing, dispensing and patient use of medicine. ${ }^{4}$

Drug use evaluation is a system of ongoing, systematic, criteria-based drug evaluation ensuring appropriate drug usage. Despite complexity of drug use, a number of indicators have been developed, standardized and evaluated by World Health Organization (WHO) which has been grouped in to three categories namely: prescribing indicators, patient care indicators and facility indicators.

These indicators are based on the practices observed in a sample of clinical encounters taking place at outpatient health facilities for the treatment of acute or chronic illnesses and measure the performance of health care providers in several key dimensions related to the appropriate usage of drugs. ${ }^{5}$ Skin diseases in developing countries have a serious impact on people's quality of life. According to WHO, prevalence studies of the general population in developing countries reported high prevalence figures for skin diseases (21-87\%). Considering the economic burden the skin diseases cause owing to its high prevalence, it is of interest to study the drug use patterns of skin diseases. Periodic monitoring of drug use pattern is essential to increase the therapeutic efficacy, decrease adverse effects and provide feedback to prescribers. ${ }^{3}$

The present study was thus designed to assess the prevalence of various skin disorders and monitor, evaluate and analyze the drug use pattern using WHO drug use indicators at Out Patient Department of Dermatology of a tertiary care teaching hospital in Eastern India.

\section{METHODS}

\section{Study design}

This is a hospital-based cross-sectional observational study. The Strengthening the Reporting of Observational Studies in Epidemiology (STROBE) guidelines were used in the preparation of protocol and the manuscript.

\section{Study period}

The study was carried out over a period of six months in the Outpatient Department of Dermatology in a tertiary care teaching unit in Eastern India.

\section{Sampling}

A total of 471 prescriptions were analyzed as per the WHO recommendations on conducting drug utilization study from OPD.

\section{Study methodology}

Permission of the Institutional Ethical Committee was obtained for conducting the study. Informed consent was taken from all participants prior to their inclusion into the study. Subjects attending the Dermatology O.P.D. and willing to participate by signing informed consent document were included in the study. Those unable to comprehend for other reasons were excluded from the study.

Subjects and their accompanying family members were interviewed by a pre-structured questionnaire, and past prescriptions and case notes, wherever available, were reviewed. All decisions relating to management of the patient including drugs and investigations were taken by the treating physician only. Investigator did not interfere in the management of patient and only observed the proceedings.

Patient related information (age, sex, and diagnosis) and drug-related information (drugs, dose, dosage form, route of administration) were recorded on a pre-structured, customized data collection sheet. The data of the patients attending the Dermatology OPD, during the study period, were included. The sampling frame was fixed as ten prescriptions per day, two days a week (including one female and one male OPD) during the given sampling period. In case of OPD holidays, the prescriptions of that day were assigned to the next working day.

The prescribed drugs were classified according to the Anatomical Therapeutic Chemical (ATC) - Defined Daily Dose (DDD) classification. Drug use pattern was as sessed and evaluated using WHO core drug use indicators which are the following:

\section{Prescribing indicators}

- Average number of drugs per prescription

- Percentage of drugs prescribed by generic name

- Percentage of encounters with an antibiotic prescribed

- Percentage of encounters with a steroid prescribed

- Percentage of encounters with an injection prescribed

- Percentage of prescribed drugs featuring in National Essential Drugs List or Formulary (NLEM 2015) of India. $^{6}$

- Percentage of drugs prescribed by FDCs

\section{Patient care indicators}

- Average consultation time

- Average dispensing time 
- Percentage of drugs actually dispensed

- Percentage of drugs adequately labelled

- Patient's knowledge of correct dosage

\section{Health facility indicators}

- Availability of copy of essential drugs list or formulary

- Availability of key drugs

Data were coded, checked for completeness and consistency. Then the data were entered and analyzed. Results were expressed in terms of Percentages and presented using tables according to the types of tool used. Descriptive statistical analysis was performed using softwares like Microsoft excel 2007 and Statistical Package for Social Science (SPSS), version 17.0.

\section{RESULTS}

A total of 471 prescriptions were analyzed during the entire study period. Out of which, 246 prescriptions were found female $(52.23 \%)$, while 225 prescriptions $(47.77 \%)$ were found to be those of male. The age group 30-39 yrs was accounted for the highest number of 168 (35.67\%) of patients. (Table 1).

Table 1: Age group distribution.

\begin{tabular}{|llll|}
\hline Age Group & Male & Female & Total \\
\hline$<10$ yrs & 6 & 7 & 13 \\
\hline $10-19$ yrs & 15 & 14 & 29 \\
\hline $20-29$ yrs & 57 & 69 & $126(26.75)$ \\
\hline $30-39$ yrs & 80 & 88 & $168(35.67)$ \\
\hline $40-49$ yrs & 47 & 46 & $93(19.74)$ \\
\hline $50-59$ yrs & 15 & 13 & 28 \\
\hline$\geq 60$ yrs & 5 & 9 & 14 \\
\hline Total & 225 & 246 & 471 \\
\hline
\end{tabular}

Total number of drugs in 471 prescriptions was found to be 1050. Number of drugs per prescription varied from 1 to 6 with average of 2.22. Most of the prescription consists of minimum of 3 drugs (207 prescriptions, $43.95 \%$ ) (Table 2).

Table 2: Drugs prescribed per prescription.

\begin{tabular}{|lll|}
\hline $\begin{array}{l}\text { Drugs per } \\
\text { prescriptions }\end{array}$ & $\begin{array}{l}\text { No. of } \\
\text { prescriptions }\end{array}$ & Total no. of drugs \\
\hline 1 & 59 & 59 \\
\hline 2 & 172 & 344 \\
\hline 3 & 207 & 621 \\
\hline 4 & 15 & 60 \\
\hline 5 & 10 & 50 \\
\hline 6 & 8 & 48 \\
\hline
\end{tabular}

The most commonly prescribed drugs were antibiotics (56.26\%), followed by steroids and steroidalcombinations
(51.8\%), and antihistamines (40.97\%) respectively (Table 3).

Table 3: Prescribing spectrum for various drug classes.

\begin{tabular}{|lll|}
\hline Drug Class & $\begin{array}{l}\text { Prescribing } \\
\text { frequency }\end{array}$ & Percentage \\
\hline Antibiotics & 265 & 56.26 \\
\hline Analgesics & 10 & 2.12 \\
\hline Antiviral & 13 & 2.76 \\
\hline Antifungal & 177 & 37.57 \\
\hline Antihistamines & 193 & 40.97 \\
\hline $\begin{array}{l}\text { Emollients and } \\
\text { protectives }\end{array}$ & 67 & 14.22 \\
\hline Vitamins and minerals & 25 & 5.31 \\
\hline $\begin{array}{l}\text { Steroids and } \\
\text { combinations }\end{array}$ & 244 & 51.8 \\
\hline $\begin{array}{l}\text { Others (antiseptics, } \\
\text { anti-acne preparation, } \\
\text { keratolytics etc.) }\end{array}$ & 56 & 11.89 \\
\hline
\end{tabular}

The most commonly prescribed topical agents were topical steroids and its combination followed by topical antifungal agents. All systemic agents were given orally except triamcinolone (for treatment of alopecia).

Among the major therapeutic agents found among the drug category, levocetrizine was found to be the mostly prescribed antihistamine, Fluconazole among antifungal, Clobetasole and betamethasone dipropionate among steroidal agent and amoxicillin-clavulin ic acid among the antibiotics.

\section{WHO/INRUD rationaldrug-use indicators}

The drug usage was assessed as per WHO core drug use indicators (Table 4). ${ }^{7}$ Prescribing indicators revealed that out of the total 1050 individual drugs prescribed, 22 $(2.09 \%)$ were prescribed by generic names and about $18.78 \%$ of the drugs were prescribed from the WHO essentialdrug list.

A total of 1050 individual drugs were prescribed in 471 encounters. Overall, the average number of drugs per encounter was 2.22. Analyzing for antibiotic prescription showed that 287 individual antibiotics were prescribed for 471 patients.

Some patients had received more than one antibiotic, as a systemic preparation in combination with either a topical application or another systemic preparation. The proportions of encounters with at least one antibiotic prescribed shows $34.82 \%$.

Present study shows that total of $9.75 \%$ drugs prescribed as fixed drug combination, among that only $0.2 \%$ accounting as essential one. 
$51.8 \%$ of the total prescriptions encountered with a steroid prescribed while injections were found to be prescribed in $11.68 \%$ encounters. The study revealed that $14.8 \%$ of drugs were prescribed in fixed dose combinations. $24.38 \%$ drugs prescribed were under National Essential Drugs List or Formulary (NLEM 2015) of India.

Assessing the patient care indicators, average consultation time was found to be $10.5 \pm 2.03$ minutes. The average dispensing time was $5.03 \pm 1.5$ minutes. In the present setup, $13.9 \%$ drugs actually dispensed from hospital supply, of which all were adequately labelled. $11.04 \%$ of patients were having bare knowledge of correct dosage.

Health facility was assessed as per specific indicators. Copy of essential drugs list or formulary was found majorly absent, with minimal availability of key drugs.

Table 4: WHO core drug use indicators.

\begin{tabular}{|c|c|c|}
\hline \multicolumn{3}{|c|}{ WHO core drug use indicators } \\
\hline & $\begin{array}{l}\text { Average number of drugs } \\
\text { per prescription }\end{array}$ & 2.22 \\
\hline \multirow{6}{*}{$\begin{array}{l}\text { Prescribing } \\
\text { indicators }\end{array}$} & $\begin{array}{l}\text { Percentage of drugs } \\
\text { prescribed by generic name }\end{array}$ & $22(2.09 \%)$ \\
\hline & $\begin{array}{l}\text { Percentage of encounters } \\
\text { with an antibiotic prescribed }\end{array}$ & $34.82 \%$ \\
\hline & $\begin{array}{l}\text { Percentage of encounters } \\
\text { with a steroid prescribed }\end{array}$ & $51.8 \%$ \\
\hline & $\begin{array}{l}\text { Percentage of encounters } \\
\text { with an injection prescribed }\end{array}$ & $11.68 \%$ \\
\hline & $\begin{array}{l}\text { Percentage of prescribed } \\
\text { drugs featuring in National } \\
\text { Essential Drugs List or } \\
\text { Formulary (NLEM 2011) of } \\
\text { India }\end{array}$ & $0.2 \%$ \\
\hline & $\begin{array}{l}\text { Percentage of drugs } \\
\text { prescribed by FDCs }\end{array}$ & $9.75 \%$ \\
\hline \multirow{5}{*}{$\begin{array}{l}\text { Patient } \\
\text { care } \\
\text { indicators }\end{array}$} & Average consultation time & $\begin{array}{l}10.5 \pm 2.03 \\
\text { minutes }\end{array}$ \\
\hline & Average dispensing time & $\begin{array}{l}5.03 \pm 1.5 \\
\text { minutes. }\end{array}$ \\
\hline & $\begin{array}{l}\text { Percentage of drugs actually } \\
\text { dispensed }\end{array}$ & $13.9 \%$ \\
\hline & $\begin{array}{l}\text { Percentage of drugs } \\
\text { adequately labelled }\end{array}$ & All \\
\hline & $\begin{array}{l}\text { Patient's knowledge of } \\
\text { correct dosage }\end{array}$ & $11.04 \%$ \\
\hline \multirow{2}{*}{$\begin{array}{l}\text { Health } \\
\text { facility } \\
\text { indicators }\end{array}$} & $\begin{array}{l}\text { Availability of copy of } \\
\text { essential drugs list or } \\
\text { formulary }\end{array}$ & $\begin{array}{l}\text { Majorly } \\
\text { Absent }\end{array}$ \\
\hline & Availability of key drugs & $\begin{array}{l}\text { Minimal } \\
\text { availability }\end{array}$ \\
\hline
\end{tabular}

\section{DISCUSSION}

In tropical countries like India, the high prevalence of skin diseases remains largely influenced by varied factors like developing economy, level of literacy, social backwardness, varied climate, industrialization, access to primary healthcare, and varied cultural factors. The high prevalence rate and moderate morbidity makes dermatological conditions an important public healthcare concern.

With current status of Indian markets being flooded with over 70,000 formulations, compared to roughly 410 preparations listed on the WHO Es sential Drugs List, there are thousands of drug companies, and several companies manufacturing generic preparations using different brand names.

In addition, thousands of formulations of vitamins, tonics, and multi-drug combinations that are unique to the Indian market are manufactured and marketed regularly. This entails the drug manufacturers to enter into fierce competition, which makes them to encourage the prescribers to prescribe branded medicines. ${ }^{8}$ This not only benefits the manufacturing companies, but also results in irrational prescribing of drugs.

Thus, a clear comprehensive rational drug policy remains a mandate for every nation to ensure a proper healthcare management. Rational use of drugs is however multifaceted. Its medical, social, and economic aspects are well reflected in the definition laid by World Health Organization (WHO) which states "Rational use of drugs requires that patients receive medications appropriate to their clinical needs, in doses that meet their own individual requirements for an adequate period of time, at the lowest cost to them and their community". 9

Unfortunately, prescribing patterns do not conform to these criteria. With wide evolution of drugs used in managing dermatological conditions, there increases an essential concern to assess the drug use practices in healthcare set-ups.

The present study analysed a total of 471 prescriptions during the entire study period of six months. The age group 30-39 yrs was accounted for the highest number of patients presenting to the outpatient department. Analysis of prescribing pattern revealed that most of the prescription consisted of minimum of 3 drugs. Number of drugs per prescription varied from 1 to 6 with average of 2.22 . Unfortunately, there are many negative consequences associated with such polypharmacy.

The burden of taking multiple medications has been majorly as sociated with greater healthcare cost, increased risk of adverse drug events, drug-interactions and medication non-adherence.

With a total of 1050 drugs in 471 prescriptions, the study hints at ignorance of rational prescribing in healthcare setups. The most commonly prescribed drugs in this study set up were antibiotics, followed by steroids and steroidal combinations and antihistamines respectively. 
Rational use of drugs in primary care is mainly assessed with the help of WHO core drug use indicators which were developed as measures of performance in three general areas related to pharmaceutical prescribing practices by health providers; key elements of patient care, covering both clinical consultation and pharmaceutical dispensing; and availability of facility-specific factors which support rational use, such as key essential drugs and minimum pharmaceutical information.

The present study assessed the drug usage in the study setup using WHO core drug use indicators, which mainly contains three domains namely prescribing indicators, patient care indicators and facility indicators. Prescribing indicators revealed $2.09 \%$ generic prescription and less than $20 \%$ drugs being prescribed from the WHO essential drug list. Overall, the average number of drugs per encounter was 2.22 , which was slightly on a higher note than the ideal expected range of 1.6-1.8. A higher average number of drugs might be due to lack of sensitization of the prescribers regarding rational prescribing or due to profitable incentives to the prescribers.

Analyzing for antibiotic prescription showed that patients had received more than one antibiotic, as a systemic preparation in combination with either a topical application or another systemic preparation. The proportions of encounters with at least one antibiotic prescribed show $34.82 \%$, which was high compared to the standard (20.0\%-26.8\%) derived to be ideal.

This result thus confers that antibiotic prescribing need to be well- regulated. There must be a antibiotic usage guidelines which needs to be followed nationwide such as to regulate irrational antibiotic prescribing thus combating antibiotic resistance.

With $11.68 \%$ encounters in which injections were prescribed, the figure remains below the ideal range of $13.4 \%-24.1 \%$. Present study shows that total of $9.75 \%$ drugs prescribed as fixed drug combination, among that only $0.2 \%$ accounting as essential one. $51.8 \%$ of the total prescriptions encountered with a steroid prescribed. The study revealed that $14.8 \%$ of drugs were prescribed in fixed dose combinations. $24.38 \%$ drugs prescribed were under National Essential Drugs List or Formulary (NLEM 2015) of India.

Patients enter facilities with a set of symptoms and complaints, and with expectations about the care they will receive; they typically leave with a package of drugs or with a prescription to obtain them in the private market. ${ }^{7}$ The patient care indicators address key aspects of what patients experience at health facilities, and how well they have been prepared to deal with the pharmaceuticals that have been prescribed and dispensed.

Assessing the patient care indicators, average consultation time was found to be $10.5 \pm 2.03$ minutes. The average dispensing time was $5.03 \pm 1.5$ minutes. In the present setup, $13.9 \%$ drugs actually dispensed from hospital supply, of which all were adequately labelled. $11.04 \%$ of patients were having bare knowledge of correct dosage. Such statistics necessitates the need to sensitize the patients regarding proper dosage details while prescribing by the healthcare professionals.

The ability to prescribe drugs rationally is influenced by various features of the working environment. Thus two particularly important components of health facility indicators are an adequate supply of essential drugs and access to unbiased information about these drugs. ${ }^{7}$

Health facility was assessed as persuch specific indicators. Copy of essential drugs list or formulary was found majorly absent, with minimal availability of key drugs. Availability of essential drug list in a healthcare setting seems to be a mandate in order to enforce rational drug prescribing. Availability of key drugs in generic mode is necessary in order to minimise the rampant practices of the drug market, thereby decreasing the healthcare cost.

Our study had certain limitations. The smaller sample size and homogeneity of the population could not make this data a representative of national statistics. However, this remains as a further scope of this study.

\section{CONCLUSION}

With ever increasing dermatological complications in a tropical country like India clubbed with other related factors, dermatology is the most sought-after speciality. Increasing dermatological prescribing has necessitated assessment of their rational usage. WHO core drug use indicators have been used in the present study as a measure of performance of drug usage. Promoting rational drug use policy is recommended for effective healthcare management.

Funding: No funding sources

Conflict of interest: None declared

Ethical approval: The study was approved by the Institutional Ethics Committee

\section{REFERENCES}

1. Nerurkar RP, Kokane MR, Mehta MN. Study of prescribing pattern of topical corticosteroids in dermatology out patients department in a tertiary care hospital in India. Int $\mathrm{J}$ Basic Clin Pharmacol. 2016;5:2194-8.

2. Patel NG, Patel NJ. Epidemiological Study of Skin (Dermatological) Diseases and its treatment in North Gujarat. Asian Journal of Pharmaceutical and Clinical Research. 2010;3(4):40-2.

3. Mukherjee S. Asses sment of corticosteroid utilization pattern among dermatology outpatients in a tertiary care teaching hospital in Eastern India. International Journal of Green Pharmacy. 2016;10(4):178-82. 
4. Lenjisa JL, Fereja TH. A Retrospective Analysis of Prescribing Practice Based on WHO Prescribing Indicators at Four Selected Hospitals of West Ethiopia: Policy Implication. East and Central African Journal of Pharmaceutical Sciences. 2013;16:69-74.

5. World Health Organization. Fact sheet: Drug use evaluation (DUE) (drug utilization review); 2017. Available at: http://apps.who.int/medicinedocs/en/d/Js4882e/8.5.ht ml. Accessed Jan 31, 2017.

6. National List of Essential Medicines. 2015. Available at: http://www.drugscontrol.org/pdf/NLEM-2015.pdf. Accessed January 22, 2017.

7. World Health Organization. Fact sheet: WHO core drug use indicators. 2017. Available at http://apps.who.int/medicinedocs/en/d/Js2289e/3.htm 1. Accessed Jan 22, 2017.
8. Aravamuthan A, Arputhavanan M, Subramaniam K. Assessment of current prescribing practices using World Health Organization core drug use and complementary indicators in selected rural community pharmacies in Southern India. J of Pharmaceutical Policy and Practice. 2016;10(1):1.

9. Dutta A, Chakraborty S. Practice of rational drug uses in a rural area of $24 \mathrm{pgs}(\mathrm{s})$ in West Bengal. Journal of Advanced Pharmaceutical Technology \& Research. 2010;1(3):358-64.

Cite this article as: Mukherjee S, Era N, Banerjee G, Tripathi SK. Assessment of drug use practices among dermatology out-patients using WHO core drug use indicators. Int J Basic Clin Pharmacol 2017;6:2905-10. 